\title{
Nota Científica: Caracterização físico-química do óleo de abacate extraído por centrifugação e dos subprodutos do processamento
}

\author{
Scientific Note: Physicochemical characterization of avocado oil extracted by \\ centrifugation and of the process byproducts
}

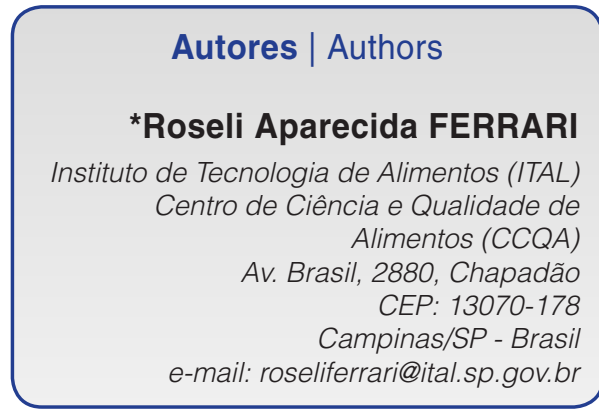

*Autor Correspondente / Corresponding Author

Recebido: Jul. 30, 2014

Aprovado: Maio 04, 2015
Resumo

O abacate é originário da América e considerado uma das plantas mais produtivas por unidade de área cultivada. Frutas com altos níveis de lipídios podem ser matéria-prima importante para a extração de óleo com substâncias bioativas que podem reduzir o risco de doenças. Este trabalho teve como objetivo a extração de óleo de abacate utilizando processo mecânico, semelhante ao empregado no azeite de oliva. À polpa triturada foi adicionada água numa proporção de 1:1, e a mistura foi mantida durante $40-60$ minutos a $45-50{ }^{\circ} \mathrm{C}$. Óleo, água e sólidos foram separados por centrifuga de três fases e o óleo filtrado. A composição físico-química do abacate e dos subprodutos do processamento foi determinada utilizando a metodologia oficial da AOCS e constou da determinação dos teores de proteínas, umidade, cinzas e lipídios (óleo). A caracterização de ácidos graxos do óleo de abacate foi determinada por cromatografia em fase gasosa. Os índices de saponificação e de iodo do óleo de abacate foram calculados com base na composição em ácidos graxos. O óleo apresentou entre 0,5 e 0,6\% de ácidos graxos livres; 5,95 a 11,89 meq $\mathrm{kg}^{-1}$ de peróxidos; 0,09-0,16\% de umidade; 0,96$1,94 \%$ de matéria insaponificável e 74,69-88,16 $\mathrm{mg} \mathrm{kg}^{-1}$ de clorofila.

Palavras-chave: Persea americana; Qualidade; Subprodutos.

\section{Summary}

The avocado originated in America, and is considered to be one of the most productive plants per unit of cultivated area. Fruits with high lipid levels may be important raw materials for the extraction of oils containing bioactive substances that could reduce the risk of diseases. This work aimed to extract avocado oil using a mechanical process, similar to that employed for olive oil. Water was added to the crushed pulp in a 1:1 ratio and the mixture maintained at $45-50{ }^{\circ} \mathrm{C}$ for $40-60$ minutes. The oil, water and solids were separated using a three phase centrifuge and the oil filtered. The physicochemical composition of the avocado and of the process byproducts was determined using official AOCS methodology, determining the protein, moisture, ash and oil contents. The fatty acid profile of the avocado oil was determined by gas chromatography, and the saponification and iodine values of the avocado oil calculated based on the fatty acid composition. The oil showed values of between 0.5 and $0.6 \%$ free fatty acids; 5.95 to 11.89 meq $\mathrm{kg}^{-1}$ of peroxides; 0.09 to $0.16 \%$ moisture; 0.96 to $1.94 \%$ of unsaponifiable matter and 74.69 to $88.16 \mathrm{mg} \mathrm{kg}^{-1}$ of chlorophyll.

Key words: Persea americana; Quality; Byproducts. 


\section{Introdução}

O abacateiro (Persea americana Mill.) é uma planta frutífera das mais produtivas por unidade de área cultivada (TANGO e TURATTI, 1992). Segundo a FAO (2014), 70\% da produção mundial de abacate está concentrada nas Américas, 13,93\% na África, 12,35\% na Ásia, 2,76\% na Europa e 1,39\% na Oceania. O Brasil, em 2012, ficou entre os 10 maiores produtores de abacate do mundo, com 159.903 t. O abacateiro é cultivado em quase todos os estados do Brasil, sendo São Paulo o principal produtor com produtividade média em torno de $21 \mathrm{t} \mathrm{ha}^{-1}$ (IBGE, 2012).

O abacate possui considerável qualidade nutritiva, com alto conteúdo de fibras, proteínas, sais minerais, destacando-se o potássio e as vitaminas, especialmente a vitamina E. O aproveitamento do óleo é, normalmente, a principal finalidade de sua industrialização, que pode render de 800 a $1.300 \mathrm{~kg} \mathrm{ha}^{-1}$, contra $330 \mathrm{~kg} \mathrm{ha}^{-1}$ do óleo de soja, fato que estimula a sua produção (KOLLER, 1992).

Tradicionalmente, o processo comercial de extração de óleo de abacate usa a fruta inteira madura e envolve a secagem, seguida da prensagem mecânica em temperatura elevada, com posterior extração com solvente orgânico. A utilização de solventes em escala comercial tem sido questionada por causa de preocupações de poluição do ar. Além disso, a remoção do solvente do óleo pode afetar a sua qualidade (RAMALHO e SUAREZ, 2013).

O óleo de abacate assemelha-se muito ao óleo de oliva, por ser extraído da polpa dos frutos e pela similaridade de suas propriedades físico-químicas, principalmente pela composição de seus ácidos graxos, predominando em ambos o ácido oléico (CANTO et al., 1980; BLEINROTH e CASTRO, 1992; SOARES et al., 1992; TANGO e TURATTI, 1992). Esses óleos são ricos em ácidos graxos ômega-9 que parecem apresentar efeitos benéficos para a saúde do consumidor, em relação à redução do risco de doenças cardiovasculares (AHMED e BARMORE, 1990; REBOLLO et al., 1998).

Estudos mostram que o consumo de dietas ricas em gorduras monoinsaturadas (ácido oleico), em substituição às gorduras saturadas, exerce seletivos efeitos fisiológicos sobre humanos, reduzindo os níveis de colesterol total, de triglicerídeos e de LDL-colesterol, sem alterar a fração HDL-colesterol do plasma (REBOLLO et al., 1998; TURATTI et al., 2002). Outra informação importante, observada com o consumo de dietas ricas em ácido oléico, foi a redução dos níveis de fibrinogênio do plasma, visto que essa fração reconhecidamente atua no desenvolvimento de lesões das artérias, servindo como prognóstico de doenças coronárias (REBOLLO et al., 1998).
O presente trabalho teve por objetivo estabelecer os parâmetros para viabilizar a extração do óleo de abacate usando processo mecânico, semelhante ao de extração de azeite de oliva, com etapa de remoção de casca e caroço, e caracterização dos produtos originados no processamento, visando colaborar para o desenvolvimento dessa cadeia produtiva.

\section{Material e métodos}

\subsection{Matéria-prima}

Frutos de abacate das variedades Hass e Fuerte foram coletados na região de Bauru, Estado de São Paulo, na safra 2013.

\subsection{Processamento}

A extração de óleo foi executada segundo Fluxograma da Figura 1. Os abacates, cerca de $1000 \mathrm{~kg}$ por dia de processamento, passaram pelo tanque de lavagem, seguiram para o despolpador marca Tortugan modelo MS-450; a polpa foi transferida com adição de água na proporção 1:1 para um tanque onde a mistura foi mantida sob agitação por $40-60$ minutos a $45-50{ }^{\circ} \mathrm{C}$, na etapa chamada de malaxagem. Em seguida, as fases óleo, água e os sólidos foram separadas em centrífuga de três fases marca Gratt modelo GMT 400, a fase óleo passou por decantador e filtro prensa marca Ecirtec modelo FPE 25/10. Como subprodutos do processamento foram separadas as cascas junto com os caroços, a fase aquosa e a de sólidos da centrifugação.

\subsection{Métodos}

Frutos de abacate das variedades Hass e Fuerte foram analisados quanto ao peso médio, teor de casca, polpa e caroço por gravimetria. A matéria-prima e os

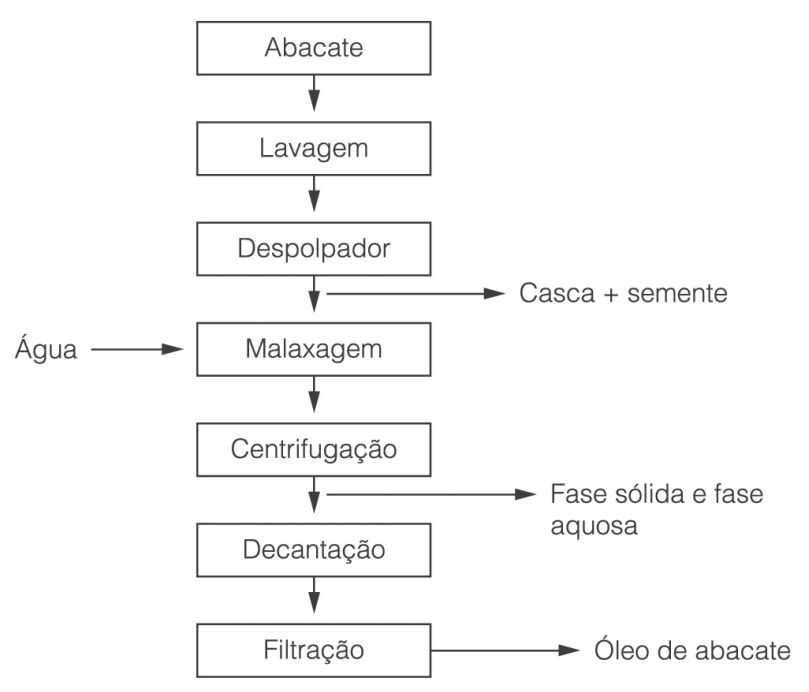

Figura 1. Fluxograma do processo de extração de óleo de abacate. 
subprodutos obtidos no processamento dos frutos foram caracterizados quanto à umidade e teor de lipídios, de proteínas e de cinzas, pelos métodos da AOCS Ba 2b-82, Ba 3-38, Ba 41-38 e Ba 5a-49, respectivamente (MEHLENBACHER et al., 2014). Os carboidratos foram calculados por diferença.

O teor de amido do caroço e a avaliação microscópica foram realizados segundo o método $\mathrm{Da}$ 25-48 adaptado (MEHLENBACHER et al., 2014).

Os óleos obtidos de três diferentes dias de processamento foram caracterizados quanto aos parâmetros de umidade e voláteis (Ca 2c-25), teor de ácidos graxos livres (Ca 5a-40), índices de iodo ( $\mathrm{Cd}$ 1b-87), saponificação (Cd 3-25), refração (Cc 7-25), peróxidos (Cd 8b-90) e matéria insaponificável (Ca 6a-40) por métodos da AOCS (MEHLENBACHER et al., 2014).

A composição em ácidos graxos do óleo foi determinada após preparo dos ésteres metílicos segundo Hartman e Lago (1973), por meio de injeção em cromatógrafo a gás com utilização de coluna capilar (Modelo: Chrompack CP-Sil 88, 100 m, 0,25 $\mathrm{mm}$ d.i., $0,20 \mu \mathrm{m}$ de filme) e detector FID (ionização em chama), operando com injetor a $270{ }^{\circ} \mathrm{C}$ e detector a $300{ }^{\circ} \mathrm{C}$, e programação de temperatura na coluna de $140{ }^{\circ} \mathrm{C}$ por $2 \mathrm{~min}$, aquecimento de $140{ }^{\circ} \mathrm{C}$ a $235^{\circ} \mathrm{C}$ $\left(2,5{ }^{\circ} \mathrm{C} / \mathrm{min}\right)$, permanecendo a $235{ }^{\circ} \mathrm{C}$ por 10 minutos, usando hidrogênio como gás de arraste. Os ácidos graxos foram identificados pelo seu tempo de retenção, comparando-se os cromatogramas da amostra com os de padrões de ésteres metílicos Mix FAME com 37 ácidos graxos identificados. A quantificação foi realizada por normalização interna (\% relativa de área), segundo metodologia oficial (MEHLENBACHER et al., 2014).

O teor de clorofila, expresso em mg de feofitina $\mathrm{kg}^{-1}$ do óleo de abacate, e a estabilidade oxidativa dos óleos foram avaliados, respectivamente, pelos métodos da AOCS Cc 13i-96 e Cd 12b-92 (MEHLENBACHER et al., 2014).

\subsection{Estatística}

Todas as análises foram realizadas em triplicata e o valor da média das medidas e o desvio-padrão, informados.

\section{Resultados e discussão}

As amostras de frutos de abacate apresentaram peso médio e teores de casca, polpa e caroço apresentados na Tabela 1. Tango et al. (2004) encontraram, para a variedade de abacate Hass, o teor de polpa de $67,5 \%$, $19,0 \%$ de caroço e $13,5 \%$ de casca, e para a variedade Fuerte, o teor de polpa de 65,8\%,22,3\% de caroço e $11,9 \%$ de casca. A proporção de cada componente dos frutos pode apresentar variações em função do grau de maturação dos mesmos.
A composição centesimal da polpa, da casca e do caroço de abacate Hass e Fuerte são apresentadas na Tabela 2.

A fração de maior interesse é a de lipídios (óleo), presente na polpa do abacate da variedade Hass em maior concentração; a casca, porém, também apresenta lipídios em quantidade apreciável e que deve ser melhor aproveitada. Os caroços das duas variedades apresentaram teores de proteínas e carboidratos superiores aos da polpa, sendo que o carboidrato predominante é o amido que está presente no caroço do abacate da variedade Hass com teor de 28,63\%, enquanto o caroço de abacate da variedade Fuerte apresentou $21,53 \%$ de amido.

O aspecto dos grânulos de amido pode ser verificado na Figura 2, com forma oval e anéis concêntricos, semelhante ao que é observado em tubérculos e raízes, dados que estão de acordo com os reportados por Kahn (1987).

Considerando a similaridade entre a polpa de abacate e os frutos da oliveira, que segundo Firestone (2005) têm composição química aproximada de 52,4\% de água, $19,6 \%$ de óleo, $1,6 \%$ de proteínas, 19,1\% de açúcares, $6,8 \%$ de celulose e $1,5 \%$ de cinzas, optou-se, neste trabalho, por adotar a tecnologia atualmente usada para extração do azeite de oliva para extrair o óleo de abacate da variedade Hass, que apresentou maior teor de lipídios, visando, dessa forma, preservar os compostos de valor nutricional. Outro fato que justifica a tecnologia escolhida é a expansão crescente da produção da cultura de oliveiras pelo Brasil, principalmente no Rio Grande do Sul, Santa Catarina, São Paulo e Minas Gerais e o interesse na industrialização desta matéria-prima (BERTONCINI et al., 2010). Para viabilizar o investimento nesse tipo de instalação industrial, a possibilidade de processar essas duas matérias-primas numa mesma instalação, minimizando a capacidade ociosa, seria de grande valia.

Amostras de óleo de abacate de três diferentes dias de processamento foram analisadas e as características reportadas na Tabela 3.

Os óleos apresentaram entre 0,52 e 0,62\% de ácidos graxos livres, teor de matéria insaponificável entre 0,96

Tabela 1. Peso médio e teores de casca, polpa e caroço de abacate das variedades Hass e Fuerte.

\begin{tabular}{lrr}
\multicolumn{1}{c}{ Determinação } & \multicolumn{2}{c}{ Abacate } \\
& \multicolumn{1}{c}{ Hass } & \multicolumn{1}{c}{ Fuerte } \\
\hline Peso médio $(g)^{\star}$ & $280,0 \pm 1,8$ & $429,1 \pm 0,9$ \\
Polpa $(\%)^{*}$ & $68,2 \pm 0,9$ & $72,8 \pm 0,8$ \\
Casca $(\%)^{*}$ & $16,1 \pm 0,4$ & $12,9 \pm 0,6$ \\
Caroço $(\%)^{*}$ & $15,7 \pm 0,5$ & $14,3 \pm 0,8$ \\
\hline
\end{tabular}

* Média e estimativa de desvio-padrão 
Nota Científica: Caracterização físico-química do óleo de abacate extraído por centrifugação e dos subprodutos do processamento FERRARI, R. A.

Tabela 2. Composição da casca, polpa e caroço de abacate das variedades Hass e Fuerte.

\begin{tabular}{|c|c|c|c|c|c|c|}
\hline \multirow{2}{*}{ Componente (\%) } & \multicolumn{3}{|c|}{ Hass } & \multicolumn{3}{|c|}{ Fuerte } \\
\hline & Polpa & Casca & Caroço & Polpa & Casca & Caroço \\
\hline Matéria seca* & $33,73 \pm 0,30$ & $29,62 \pm 0,23$ & $46,47 \pm 0,03$ & $23,78 \pm 0,31$ & $22,09 \pm 0,41$ & $40,28 \pm 0,01$ \\
\hline Proteína* & $1,63 \pm 0,02$ & $1,74 \pm 0,42$ & $2,16 \pm 0,12$ & $1,47 \pm 0,04$ & $1,67 \pm 0,05$ & $1,64 \pm 0,02$ \\
\hline Cinzas* & $1,28 \pm 0,12$ & $1,31 \pm 0,01$ & $1,18 \pm 0,01$ & $1,59 \pm 0,02$ & $1,62 \pm 0,03$ & $1,23 \pm 0,01$ \\
\hline Umidade* & $66,27 \pm 0,30$ & $70,38 \pm 0,23$ & $53,26 \pm 0,03$ & $76,22 \pm 0,31$ & $77,01 \pm 0,41$ & $59,72 \pm 0,01$ \\
\hline Lipídios* & $25,47 \pm 0,01$ & $10,10 \pm 0,07$ & $1,00 \pm 0,00$ & $15,07 \pm 0,33$ & $8,40 \pm 0,56$ & $0,94 \pm 0,08$ \\
\hline Carboidratos ${ }^{\star *}$ & $5,35 \pm 0,30$ & $16,47 \pm 0,42$ & $42,4 \pm 0,03$ & $5,65 \pm 0,31$ & $11,30 \pm 0,41$ & $36,47 \pm 0,01$ \\
\hline
\end{tabular}

* Média e estimativa de desvio-padrão. ${ }^{*}$ Calculado por diferença.
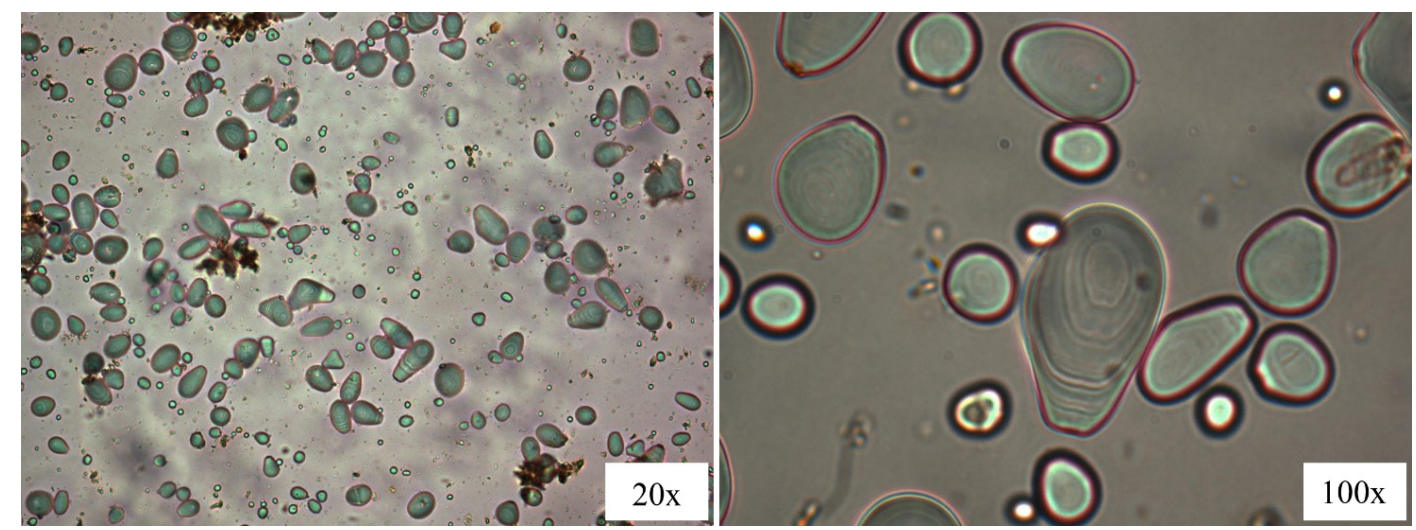

Figura 2. Aspecto dos grânulos de amido de caroço de abacate, aumento de 20 e 100x respectivamente.

Tabela 3. Características das amostras de óleo de abacate de três diferentes dias de processamento.

\begin{tabular}{|c|c|c|c|}
\hline \multirow{2}{*}{ Características } & \multicolumn{3}{|c|}{ Óleo de abacate } \\
\hline & Dia 1 & Dia 2 & Dia 3 \\
\hline \% Ácidos Graxos Livres* (oleico) & $0,62 \pm 0,01$ & $0,52 \pm 0,01$ & $0,57 \pm 0,01$ \\
\hline 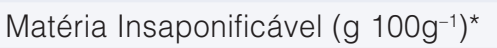 & $1,85 \pm 0,38$ & $0,96 \pm 0,30$ & $1,94 \pm 0,11$ \\
\hline Umidade e Voláteis $\left(\mathrm{g} 100 \mathrm{~g}^{-1}\right)^{\star}$ & $0,16 \pm 0,01$ & $0,11 \pm 0,01$ & $0,09 \pm 0,00$ \\
\hline Índice de Peróxido $\left(\text { meq } \mathrm{kg}^{-1}\right)^{\star}$ & $6,32 \pm 0,56$ & $5,95 \pm 0,11$ & $11,89 \pm 1,21$ \\
\hline Índice de Refração $40^{\circ} \mathrm{C}^{*}$ & $1,4620 \pm 0,0001$ & $1,4625 \pm 0,0000$ & $1,4625 \pm 0,0001$ \\
\hline Clorofila (mg de feofitina $\left.\mathrm{kg}^{-1}\right)^{\star}$ & $73,15 \pm 0,01$ & $88,16 \pm 0,02$ & $74,69 \pm 0,01$ \\
\hline Estabilidade Oxidativa $(\mathrm{h})^{\star}$ & $4,35 \pm 0,18$ & $5,24 \pm 0,08$ & $3,93 \pm 0,03$ \\
\hline
\end{tabular}

* Média e estimativa de desvio-padrão.

e 1,94\%, umidade e voláteis de 0,09 a $0,16 \%$ e variação de 5,95 a 11,89 meq $\mathrm{kg}^{-1}$ no índice de peróxido. O índice de refração variou de 1,4620 a 1,4625; o teor de clorofila encontrado na faixa de 73,15 a 88,16 mg de feofitina $\mathrm{kg}^{-1}$ e a estabilidade oxidativa apresentada foi de 3,93 a 5,24h. As amostras atendem a especificação do Codex (Stan 2101999) para óleos virgens (CODEX, 2013). Importante salientar que a ANVISA, através da Resolução RDC $n^{\circ} 270$, que estabelece o regulamento técnico para óleos vegetais no Brasil, não faz nenhuma alegação específica para o óleo de abacate. Os parâmetros para azeite de

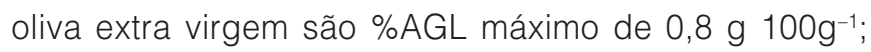
Índice de peróxidos máximo 20 meq $\mathrm{kg}^{-1}$; índice de refração variando de 1,4677 a 1,4705; e teor de matéria insaponificável máximo de $15 \mathrm{~g} \mathrm{~kg}^{-1}$ (BRASIL, 2005).
A Tabela 4 apresenta a composição em ácidos graxos e os índices de iodo e de saponificação das amostras de óleo de abacate e o padrão para azeite de oliva de acordo com a Instrução Normativa $n^{\circ} 1$, de 30 de janeiro de 2012, do Ministério da Agricultura Pecuária e Abastecimento (BRASIL, 2012), onde pode ser verificada a semelhança com o óleo de abacate. Os resultados mostraram que o óleo de abacate é composto em sua maioria de ácidos graxos insaturados, dados que são similares aos reportados por Tango et al. (2004). O teor de ácidos graxos poli-insaturados foi inferior a 14\%, considerado bom do ponto de vista da estabilidade do óleo, uma vez que este, devido à quantidade de duplas ligações, é mais susceptível à oxidação. O perfil em ácidos graxos do óleo de abacate o qualifica como um óleo comestível especial, principalmente pela presença dos ácidos oleico e linoleico, além de apresentar 
Tabela 4. Composição em ácidos graxos das amostras de óleo de abacate.

\begin{tabular}{|c|c|c|c|c|}
\hline \multirow{2}{*}{ Ácido Graxo (\%) } & \multicolumn{3}{|c|}{ Tempo (dia) } & \multirow{2}{*}{$\begin{array}{l}\text { Padrão MAPA } \\
\text { azeite de oliva }\end{array}$} \\
\hline & 1 & 2 & 3 & \\
\hline C 16:0 ácido palmítico & $23,20 \pm 0,02$ & $21,95 \pm 0,01$ & $22,77 \pm 0,00$ & 7,50 a 20,0 \\
\hline C 16:1 ácido palmitoleico & $13,13 \pm 0,01$ & $12,38 \pm 0,00$ & $12,75 \pm 0,01$ & 0,3 a 3,5 \\
\hline C 17:1 ácido heptadecenoico & $0,08 \pm 0,00$ & $0,07 \pm 0,01$ & $0,08 \pm 0,00$ & $\geq 0,3$ \\
\hline C 18:0 ácido esteárico & $0,44 \pm 0,00$ & $0,45 \pm 0,00$ & $0,44 \pm 0,00$ & 0,5 a 5,0 \\
\hline C 18:1 ácido oleico & $49,45 \pm 0,03$ & $51,24 \pm 0,02$ & $50,48 \pm 0,01$ & 55,0 a 83,0 \\
\hline C 18:2 ácido linoleico & $12,69 \pm 0,01$ & $12,85 \pm 0,00$ & $12,47 \pm 0,01$ & 3,5 a 21,0 \\
\hline C 20:1 ácido eicosenoico & $0,15 \pm 0,00$ & $0,17 \pm 0,01$ & $0,16 \pm 0,01$ & $\geq 0,4$ \\
\hline C 18:3 ácido linolênico & $0,66 \pm 0,01$ & $0,71 \pm 0,01$ & $0,67 \pm 0,01$ & $\geq 1,0$ \\
\hline$\sum$ Saturados & $23,64 \pm 0,02$ & $22,40 \pm 0,01$ & $23,21 \pm 0,03$ & $n . i^{*}$ \\
\hline$\sum$ Monoinsaturados & $62,81 \pm 0,01$ & $63,86 \pm 0,03$ & $63,47 \pm 0,02$ & $n . i^{*}$ \\
\hline$\sum$ Polinsaturados & $13,35 \pm 0,01$ & $13,56 \pm 0,00$ & $13,14 \pm 0,01$ & $n . i^{*}$ \\
\hline Índice de iodo $\left(\mathrm{gl}_{2} 100 \mathrm{~g}^{-1}\right)$ & $78,80 \pm 0,01$ & $80,10 \pm 0,01$ & $79,00 \pm 0,01$ & 75 a 94 \\
\hline Índice de saponificação (mg KOH g ${ }^{-1}$ ) & $197,24 \pm 0,01$ & $196,81 \pm 0,03$ & $197,05 \pm 0,02$ & 184 a 196 \\
\hline
\end{tabular}

${ }^{*}$ n.i. Não informado.

Tabela 5. Composição dos subprodutos do processamento de extração do óleo de abacate.

\begin{tabular}{lccc}
\multicolumn{1}{c}{ Componente (\%) } & $\begin{array}{c}\text { Subproduto } \\
\text { Sólidos }\end{array}$ & Fase aquosa \\
\hline Proteína $(\mathrm{N} \times 5,75)^{*}$ & $2,09 \pm 0,04$ & $0,89 \pm 0,04$ & $0,48 \pm 0,00$ \\
Cinzas* & $1,19 \pm 0,01$ & $0,46 \pm 0,01$ & $0,38 \pm 0,00$ \\
Umidade* $^{*}$ & $59,26 \pm 0,32$ & $87,80 \pm 0,04$ & $96,26 \pm 0,03$ \\
Lipídios $^{*}$ & $4,91 \pm 0,00$ & $2,06 \pm 0,05$ & $1,33 \pm 0,01$ \\
Carboidratos** $^{*}$ & $32,55 \pm 0,32$ & $8,79 \pm 0,05$ & $1,55 \pm 0,03$ \\
\hline
\end{tabular}

* Média e estimativa de desvio-padrão. ${ }^{* *}$ Calculado por diferença.

predominantemente em sua composição, ácidos graxos monoinsaturados (mais de $62 \%$ ) e polinsaturados (mais de $13 \%$ ), ambos recomendados para redução do risco de doenças cardiovasculares (ANTONIASSI et al., 1998).

A composição dos subprodutos gerados no processamento proposto de extração do óleo de abacate da variedade Hass, casca e caroço, fase sólida e aquosa da centrifugação, pode ser observada na Tabela 5.

Deve-se ressaltar que a casca mais caroço apresentaram valores apreciáveis de carboidratos e lipídios. Segundo Tango et al. (2004), as sementes dos frutos das cultivares ricas em óleo nas polpas apresentam teores de amido acima da média geral. Quanto à fase de sólidos, que contempla a polpa de abacate após extração dos lipídios, observa-se em maior volume a presença de carboidratos, com rápido escurecimento perceptível a olho nu, provocado pela ação da enzima polifenoloxidase, presente em alta concentração no abacate, conforme relatado por Lupetti et al. (2003).

\section{Conclusões}

A extração do óleo de abacate a partir de frutos da variedade Hass utilizando o processo de obtenção de azeite de oliva adaptado é possível e ambos podem ser produzidos na mesma instalação industrial.
Os resultados das análises de composição do óleo de abacate confirmam a possibilidade de utilizá-lo para consumo humano e na indústria de alimentos.

Os subprodutos do processo de extração de óleo proposto neste trabalho apresentam compostos de interesse, como os lipídios presentes na casca e o teor de amido presente no caroço.

\section{Agradecimentos}

Ao Conselho Nacional de Desenvolvimento Científico e Tecnológico - CNPq, pelo apoio. À empresa Jaguacy Avocado Brasil, pelo fornecimento das amostras de abacate.

\section{Referências}

AHMED, E. M.; BARMORE, C. R. Avocado. In: NAGY, S.; SHAW, P. E.; WARDOWSKI, W. F. (Ed.). Fruits of tropical and subtropical origin: composition, properties and uses. Lake Alfred: AVI Publishing, 1990. p. 121-156.

ANTONIASSI, R.; PEÇANHA, B. R. B.; LAGO, R. C. A. Efeito da adição de óleo de abacate na estabilidade oxidativa de óleos de soja e girassol. In: CONGRESSO BRASILEIRO DE CIÊNCIA E TECNOLOGIA DE ALIMENTOS, 16., 1998, Rio de Janeiro. Anais... Campinas: UNICAMP, 1998. 
Nota Científica: Caracterização físico-química do óleo de abacate extraído por centrifugação e dos subprodutos do processamento FERRARI, R. A.

BERTONCINI, E. I.; TERAMOTO, J. R. S.; PRELA-PANTANO, A. Desafios para produção de azeite no Brasil. Campinas: Infobibos, 2010. Disponível em: <http://www.infobibos.com/ Artigos/2010_4/DesafioOliva/index.htm>. Acesso em: 18 jul. 2014.

BLEINROTH, E. W.; CASTRO, J. V. Matéria-prima. In: ABACATE: cultura, matéria-prima, processamento e aspectos econômicos. Campinas: ITAL, 1992. p. 58-147.

BRASIL. Agência Nacional de Vigilância Sanitária. Resolução RDC n² 270, de 22 de setembro de 2005. Regulamento técnico para óleos vegetais, gorduras vegetais e creme vegetal. Diário Oficial [da] República Federativa do Brasil, Brasília, DF, 23 set. 2005. Disponível em: <http://portal.anvisa.gov.br/wps/wcm/ connect/82d8d2804a9b68849647d64600696f00/RDC_n_270. pdf?MOD=AJPERES >. Acesso em: 18 jul. 2014.

BRASIL. Ministério da Agricultura, Pecuária e Abastecimento - MAPA. Instrução Normativa n 1, de 30 de janeiro de 2012. Diário Oficial [da] República Federativa do Brasil, Brasília, DF, 1 fev. 2012. Disponível em: <http://www.azeiteonline.com. br/?page_id=168>. Acesso em: 18 jan. 2013.

CANTO, W. L.; SANTOS, L. C.; TRAVAGLINI, M. M. E. Óleo de abacate: extração, usos e seus mercados atuais no Brasil e na Europa. Campinas: ITAL, 1980. 144 p. (Estudos Econômicos).

CODEX ALIMENTARIUS - CODEX. Codex Stan 210-1999: codex standard for named vegetable oils. Geneva: WHO/FAO, 2013. 16 p. Disponível em: <www.codexalimentarius.org/input/.../ CXS_210e.pdf>. Acesso em: 18 jan. 2013.

FIRESTONE, D. Olive oil. In: SHAHIDI, F. (Ed.). Bailey's industrial oil \& fats products. 6th ed. Hoboken: John Wiley \& Sons, 2005. cap. 7. p. 303-328. (v. 2). http://dx.doi.org/10.1002/047167849X. bio029.

FOOD AND AGRICULTURE ORGANIZATION OF THE UNITED NATIONS - FAO. Commodities by country: top production - world - 2012. Rome. Disponível em: <http://faostat.fao.org/ site/339/default.aspx>. Acesso em: 18 jan. 2014.

HARTMAN, L.; LAGO, R. C. A. Rapid preparation of fatty acid methyl esters from lipids. Laboratory Practice, London, v. 22, n. 6, p. 475-476, 1973. PMid:4727126.

INSTITUTO BRASILEIRO DE GEOGRAFIA E ESTATÍSTICA IBGE. Produção agrícola municipal. Brasília. Disponível em: <http://www.ibge.gov.br>. Acesso em: 22 nov. 2012.
$\mathrm{KAHN}, \mathrm{V}$. Characterization of starch isolated from avocado seeds. Journal of Food Science, Champaign, v. 52, n. 6, p. 1646-1648, 1987. http://dx.doi.org/10.1111/j.1365-2621.1987. tb05896.x.

KOLLER, O. C. Abacaticultura. Porto Alegre: UFRGS, 1992. $38 \mathrm{p}$.

LUPETTI, K. O.; RAMOS, L. A.; FATIBELLO-FILHO, O. Determinação enzimática de dopamina em formulações farmacêuticas utilizando sistema de análise por injeção em fluxo com extrato bruto de abacate (Persea americana). Quimica Nova, São Paulo, v. 26, n. 2, p. 197-201, 2003. http://dx.doi. org/10.1590/S0100-40422003000200010.

MEHLENBACHER, V. C.; SALLEE, E. M.; HOPPER, T. H.; LINK, W. E.; WALKER, R. O.; FIRESTONE, D. (Ed). Official methods and recommended practices of the AOCS. 6th ed. 3rd printing. Urbana: AOCS, 2014.

RAMALHO, H. F.; SUAREZ, P. A. Z. A química dos óleos e gorduras e seus processos de extração e refino. Revista Virtual Química, Niterói, v. 5, n. 1, p. 2-15, 2013.

ReBollo, A. J. G.; BotejarA, E. M.; CANSADO, A. O.; MORALES, P. J.; BELLIDO, M. M.; SÁNCHEZ, A. F.; ARIAS, P. M.; ALVAREZ, J. E. C. Effects of consumption of meat product rich in monounsaturated fatty acids (the ham from the Iberian pig) on plasma lipids. Nutrition Research, New York, v. 18, n. 4, p. 743-750, 1998. http://dx.doi.org/10.1016/S02715317(98)00060-8.

SOARES, S. E.; MANCINI FILHO, J.; DELLA MODESTA, R. C. Sensory detection limits of avocado oil in mixtures with olive oil. Revista Española de Ciencia y Tecnologia de Alimentos, España, v. 32, n. 5, p. 509-516, 1992.

TANGO, J. S.; CARVALHO, C. R. L.; SOARES, N. B. Caracterização física e química de frutos de abacate, visando o seu potencial para extração de óleo. Revista Brasileira de Fruticultura, Jaboticabal, v. 26, n. 1, p. 17-23, 2004. http://dx.doi.org/10.1590/ S0100-29452004000100007.

TANGO, J. S.; TURATTI, J. M. Óleo de abacate. In: ABACATE: cultura, matéria-prima, processamento e aspectos econômicos. Campinas: ITAL, 1992. cap. 4, p. 156-192.

TURATTI, J. M.; GOMES, R. A. R.; ATHIÉ, I. Lipídios: aspectos funcionais e novas tendências. Campinas: ITAL, 2002. 78 p. 